\title{
Three-dimensional quantification of cardiac surface motion: A newly developed three-dimensional digital motion-capture and reconstruction system for beating heart surgery
}

Toshiki Watanabe, MD, ${ }^{a}$ Sadao Omata, PhD, ${ }^{\mathrm{c}}$ Motoki Odamura, PhD, ${ }^{\mathrm{b}}$ Masahumi Okada, PhD, Yoshihiko Nakamura, PhD, and Hitoshi Yokoyama, MDa

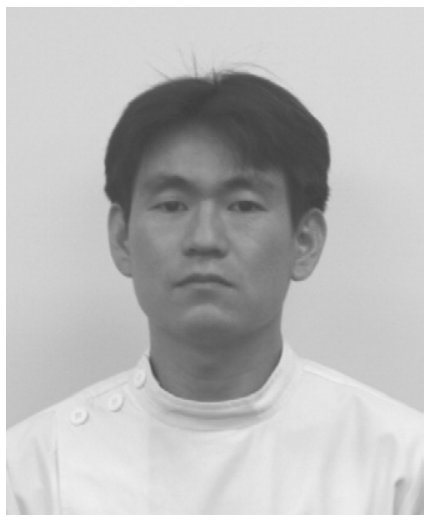

Dr Watanabe
From the Department of Cardiovascular Surgery, Fukushima Medical University, ${ }^{\text {a }}$ Fukushima, Japan; Department of MechanoInformatics, Graduate School of Information Science and Technology, University of Tokyo, ${ }^{\text {b }}$ Tokyo, Japan; and the Department of Electrical and Electronics Engineering, College of Engineering, Nihon University, Koriyama, Japan.

Received for publication March 22, 2006; revisions received May 17, 2006; accepted for publication July 7, 2006.

Address for reprints: Toshiki Watanabe, MD, 1 Hikarigaoka, Fukushima City, Fukushima prefecture, Japan (E-mail: watatoshi@mua. biglobe.ne.jp)

J Thorac Cardiovasc Surg 2006;132:1162-71 $0022-5223 / \$ 32.00$

Copyright $\odot 2006$ by The American Association for Thoracic Surgery

doi:10.1016/j.jtcvs.2006.07.017
Objective: This study aimed to evaluate our newly developed 3-dimensional digital motion-capture and reconstruction system in an animal experiment setting and to characterize quantitatively the three regional cardiac surface motions, in the left anterior descending artery, right coronary artery, and left circumflex artery, before and after stabilization using a stabilizer.

Methods: Six pigs underwent a full sternotomy. Three tiny metallic markers (diameter $2 \mathrm{~mm}$ ) coated with a reflective material were attached on three regional cardiac surfaces (left anterior descending, right coronary, and left circumflex coronary artery regions). These markers were captured by two high-speed digital video cameras (955 frames per second) as 2-dimensional coordinates and reconstructed to 3-dimensional data points (about 480 xyz-position data per second) by a newly developed computer program.

Results: The remaining motion after stabilization ranged from 0.4 to $1.01 \mathrm{~mm}$ at the left anterior descending, 0.91 to $1.52 \mathrm{~mm}$ at the right coronary artery, and 0.53 to $1.14 \mathrm{~mm}$ at the left circumflex regions. Significant differences before and after stabilization were evaluated in maximum moving velocity (left anterior descending $456.7 \pm 178.7$ vs $306.5 \pm 207.4 \mathrm{~mm} / \mathrm{s}$; right coronary artery $574.9 \pm 161.7$ vs $446.9 \pm 170.7 \mathrm{~mm} / \mathrm{s}$; left circumflex $578.7 \pm 226.7 \mathrm{vs} 398.9 \pm 192.6 \mathrm{~mm} / \mathrm{s} ; P<$ .0001 ) and maximum acceleration (left anterior descending $238.8 \pm 137.4 \mathrm{vs}$ $169.4 \pm 132.7 \mathrm{~m} / \mathrm{s}^{2}$; right coronary artery $315.0 \pm 123.9$ vs $242.9 \pm 120.6 \mathrm{~m} / \mathrm{s}^{2}$; left circumflex $307.9 \pm 151.0$ vs $\left.217.2 \pm 132.3 \mathrm{~m} / \mathrm{s}^{2} ; P<.0001\right)$.

Conclusions: This system is useful for a precise quantification of the heart surface movement. This helps us better understand the complexity of the heart, its motion, and the need for developing a better stabilizer for beating heart surgery.

$\mathrm{R}$ ecently, off-pump coronary artery bypass (OPCAB) has become more frequent in surgical procedures. Mechanical stabilization of the anastomotic area of the target vessel is an essential technique in coronary bypass surgery on the beating heart. Stabilizers are used to reduce the cardiac surface movement. However, OPCAB is still described as technically difficult because of the complexity of beating heart coronary artery surgery. Ample training before operating on patients is necessary and the skill that only a seasoned surgeon retains is essential. It is difficult to suture the coronary artery when the residual motion after stabilization is still a factor and/or an unexpected reaction takes place, such as an arrhythmia. In telerobotic surgery, it has been reported that the current stabilization with a stabilizer was insufficient and improvement of the stabilizer and new technology of stabilization is necessary. ${ }^{1}$ Attempts have been made to develop virtual stabilization, 


\section{Abbreviations and Acronyms \\ LAD = left anterior descending coronary artery \\ LCX = left circumflex coronary artery \\ $\mathrm{OPCAB}=$ off-pump coronary artery bypass \\ $\mathrm{RCA}=$ right coronary artery}

in which the surgeon sees a stationary image and the point of interest on a monitor and the motion of the point is calculated with robotic synchronization. ${ }^{2,3}$ To this point, some methods have been developed to analyze cardiac surface motion. ${ }^{4-9}$ However, a more detailed analysis of the cardiac surface motion is needed to calculate the amount of motion, velocity, and acceleration of the beating heart. This study was aimed to evaluate our newly developed 3-dimensional digital motion-capture and reconstruction system in an animal-based experiment and to characterize quantitatively the three regional cardiac surface motions in the left anterior descending artery (LAD), right coronary artery (RCA), and left circumflex artery (LCX) before and after stabilization of the heart.

\section{Materials and Methods}

\section{Anesthesia and Hemodynamic Monitoring}

Six pigs weighing $49 \pm 17 \mathrm{~kg}$ were used. All animals were treated humanely in compliance with the "Principles of Laboratory Animal Care" formulated by the National Society for Medical Research and the "Guide for the Care and Use of Laboratory Animals" prepared by the Institute of Laboratory Animal Resources and published by the National Institutes of Health (Publication No. 86-23, revised 1985). After sedation with a mixture of ketamine hydrochloride $(20 \mathrm{mg} / \mathrm{kg})$, atropine sulfate $(1 \mathrm{mg})$, and pentobar- bital sodium $(30 \mathrm{mg} / \mathrm{kg})$ intramuscularly in the neck, the animals were placed on the operating table in a supine position and the external electrocardiogram was monitored. An ear vein was cannulated for fluid and drug administration. After endotracheal intubation, mechanical positive-pressure ventilation was maintained with a mixture of $100 \%$ oxygen and isoflurane at a tidal volume of $10 \mathrm{~mL} / \mathrm{kg}$. Anesthesia was maintained by isoflurane gas $(0.5 \%$ $5 \%)$ and bolus infusion of pentobarbital $\left(10 \mathrm{mg} \cdot \mathrm{kg}-{ }^{1} \cdot \mathrm{h}-{ }^{1}\right)$. The arterial blood pressure of the femoral artery was continuously monitored. After median sternotomy, the pericardium was opened. A Swan-Ganz catheter (Baxter Healthcare, Irvine, Calif) was inserted from the right atrial appendage into the pulmonary artery, and pulmonary arterial pressure, right atrial pressure, and cardiac output were continuously monitored.

The sinus node was destroyed by liquid nitrogen, and temporary epicardial pacemaker wires were sutured on the right atrium. The heart rate was controlled by electrical pacing. ${ }^{10,11}$

\section{Data Acquisition System}

A schematic overview of this newly developed system is shown in Figure 1. This system consisted of two computers for processing, two high-speed digital video cameras, and two light sources. Each computer had an image-processing board (Viper digital; Coreco Inc, Saint Laurent, Quebec, Canada) that provided real-time picture taking from a high-speed digital camera. These two high-speed 8-bit digital video cameras (DALSA-CA-D6; $260 \times 260$ pixels, with a frame rate of 955 frames per second [fps], DALSA Inc, Waterloo, Ontario, Canada), were attached to two endoscopes (Hopkins; Karl Storz GmbH \& Co, Tuttlingen, Germany) with two light sources (XENON 300; Karl Storz). These high-speed cameras were set in a fixed position and, with the endoscope attached to them, they were able to focus in and lock onto the markers that were fixed onto the heart surface. The markers were made of stainless steel ball and had a diameter of 2 $\mathrm{mm}^{3}$. They were then coated with a retroreflective material (a material that has the ability to reflect light in an incidence direction) that can be

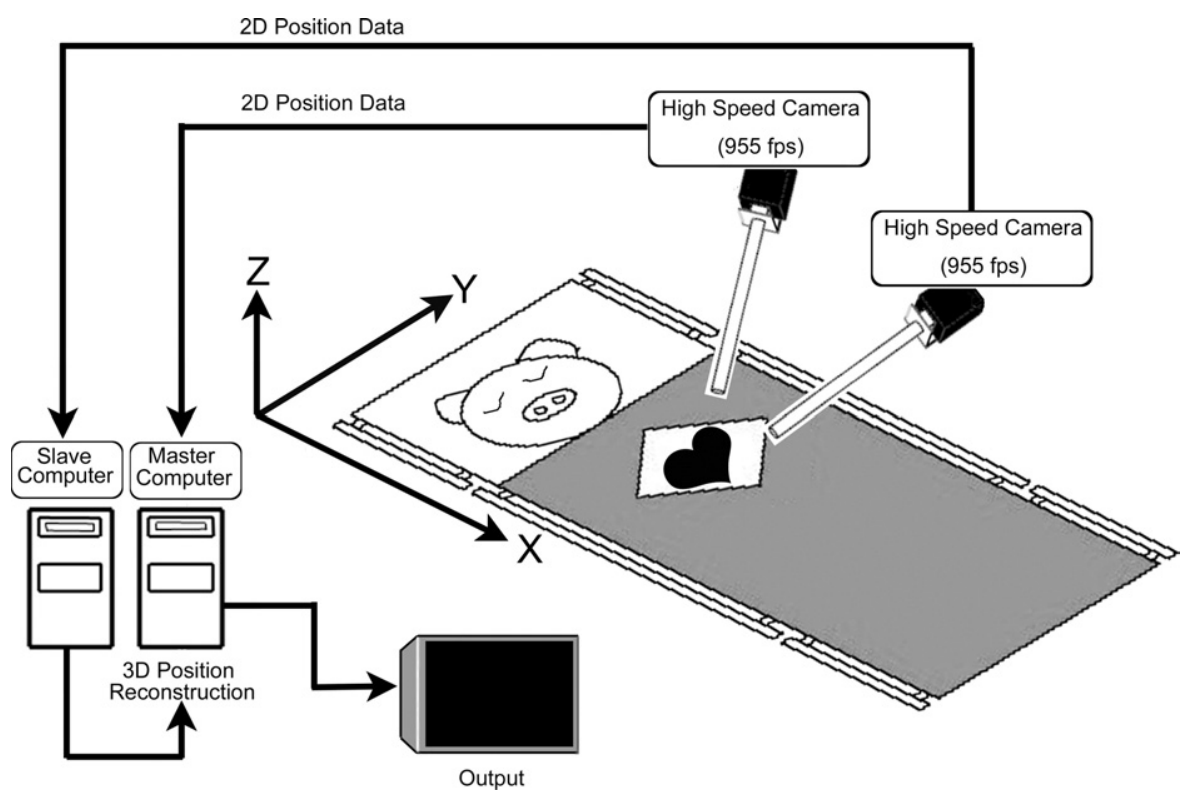

Figure 1. A schematic overview of this newly developed system. The $X$-axis was classified as the direction from the "head to tail" of the pig, the $Y$-axis was classified as the "left to right" side of the operating table, and the Z-axis was classified as the "upward" vertical angle from the pig. 2D, Twodimensional; 3D, 3-dimensional. 


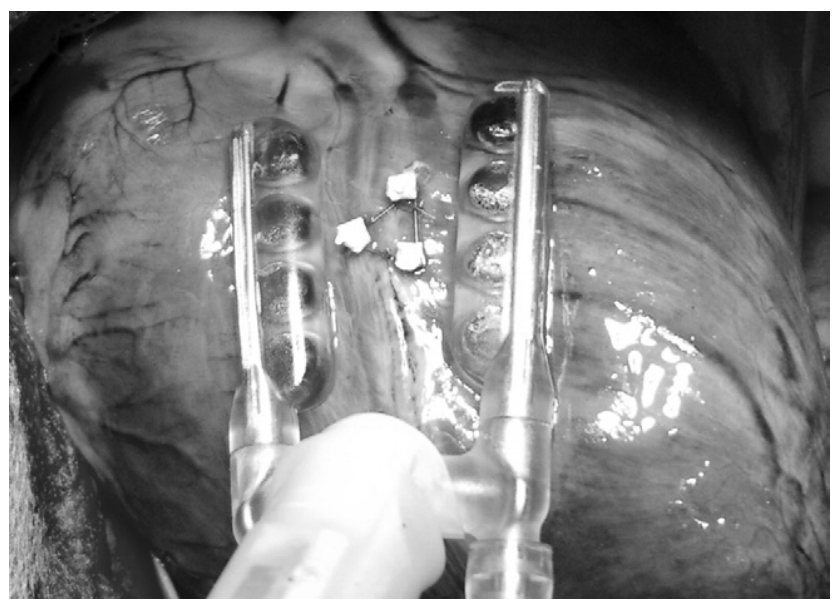

Figure 2. Fixing three markers to a target point (the left anterior descending coronary artery) under stabilization by 0 ctopus 4.3 stabilizer. Each marker was connected by titanium wire and fixed on epicardium by 6-0 polypropylene.

seen by the endoscope and the high-speed cameras. These high-speed cameras were able to recognize the bright light that was emitted because of the high frame bit rate $(955 \mathrm{fps})$ that was used in this experiment. An exposure time per frame shortens when frame rate per second is increased. The light that a retroreflective material reflects was sufficiently bright. The movement and tracking of the markers and the heart's movements were then carried out by computer processing. The data reliability was increased by fixation of three markers to the target point in a triangular shape (Figure 2), and tracking was performed by a template-matching method. ${ }^{12-16}$ This template-matching method is commonly used in image processing as well as object recognition and motion tracking. First, we acquired a still of the image and scanned the brightness value of all pixels. When light points were discovered, we searched for the circumference and recognized a triangle form of three markers. In the next frame, we searched for the markers around the triangle only and compared a newly recognized triangle with the triangle that we recognized one frame before. When two triangles accord, a newly recognized triangle is decided as the markers. Motion tracking of markers was carried out by repeating this step. We calculated a center of gravity of the triangle at the same time and defined it as a position of the target on the heart. Three markers were connected by titanium wire (length was $4 \mathrm{~mm}$ ) to maintain the form of a triangle and were fixed on the epicardium by 6-0 polypropylene suture. Not only were these cameras able to converge onto these markers regardless of light conditions, but also they were able to deflect unwanted reflections or distractions given from other parts of the body. The triangle shape was calculated as follows:

$$
\begin{gathered}
d(p, q, r)=\left(\left\|m_{p}\right\|-\left\|m_{q}\right\|\right)^{2}+\left(\left\|m_{q}\right\|-\left\|m_{r}\right\|\right)^{2}+\left(\left\|m_{r}\right\|-\left\|m_{p}\right\|\right)^{2} \\
(1 \leq p \leq n-2, p \leq q \leq n-1, q \leq r \leq n)
\end{gathered}
$$

where $m_{i}$ is movement distance of a light point $M_{i}(i=1,2, \ldots, n)$. The three triangular tops $\left(M_{p}, M_{q}, M_{r}\right)$ are calculated by minimizing $d(p, q, r)$.
TABLE 1. Camera parameters

\begin{tabular}{cc}
\hline $\begin{array}{c}\text { Intrinsic parameters } \\
f_{i}\end{array}$ & $\begin{array}{c}\text { Focus distance } \\
S_{u i}, S_{v i}\end{array}$ \\
$\left(U_{c i}, V_{c i}\right)^{T}$ & $\begin{array}{c}\text { Substantial vertical, horizontal size of } \\
\text { The center of the radial distortion on } \\
\text { the image in the ultraviolet } \\
\text { coordinate system }\end{array}$ \\
$\begin{array}{c}\text { Extrinsic parameters } \\
R_{i}\end{array}$ & $\begin{array}{c}\text { The rotation matrix from the world } \\
\text { coordinate system to the camera } \\
\text { coordinate system }\end{array}$ \\
$t_{i}$ & $\begin{array}{c}\text { The origin position of the camera } \\
\text { coordinate in the world coordinate } \\
\text { system }\end{array}$ \\
\hline
\end{tabular}

Once the cameras were able to acquire 2-dimensional coordinates from the markers through the high-speed cameras, the master computer was used to compare the data given from each camera and create a 3-dimensional data point in real time. These real-time data points were created through a program that was uniquely prepared for this experiment. This program was developed by our team with the aid of $\mathrm{C}^{++}$(Microsoft, Inc, Redmond, Wash).

When we perform 3-dimensional position measurement using a camera, it is necessary to demand the intrinsic parameters that are peculiar to an optical system of the camera and the extrinsic parameters determined by the position of the camera. The lists of parameters are shown in Table 1. In addition, some distortion exists in a 2-dimensional coordinate, $p=(u, v)^{T}$, obtained from a camera depending on the optics characteristics of the camera. In this system, distortion is revised by an approximation to the trinomial using a radial distortion model that distortion arises in proportion to distance from the center of an image radially. ${ }^{17} \mathrm{~A}$ 2-dimensional coordinate on the camera $i(i$ $=1,2)$ image after revision is denoted by $P_{i}=\left(U_{i}, V_{i}\right)^{T}$. A 3-dimensional coordinate in a camera coordinate system is denoted by $w_{i}=$ $\left(x_{i}, y_{i}, z_{i}\right)^{T}$. A 3-dimensional coordinate in the world coordinate system is denoted by $W=(X, Y, Z)^{T}$. The relationship between $P_{i}$ and $w_{i}$ is given by

$$
z_{i} P_{i}=\left(\begin{array}{ccc}
-f_{i} / S_{x i} & 0 & U_{c i} \\
0 & f / S_{y i} & V_{c i}
\end{array}\right) w_{i}
$$

(2) is substituted for (1); then (3) is obtained.

$$
\begin{gathered}
z_{i} P_{i}=\left(\begin{array}{lll}
0 & 0 & U \\
0 & 0 & V
\end{array}\right) w_{i} \\
C_{i} w_{i}=0 \\
C_{i}=\left(\begin{array}{ccc}
-f_{i} / S_{x i} & 0 & U_{i}-U_{c i} \\
0 & f / S_{y i} & V_{i}-V_{c i}
\end{array}\right)
\end{gathered}
$$

(4) is given by coordinate transformation and is substituted for (3); then (5) is obtained.

$$
\begin{gathered}
w_{i}=R_{i}^{\prime} W+t^{\prime}{ }_{i} \\
R^{\prime}{ }_{i}=R^{T}{ }_{i}
\end{gathered}
$$




$$
\begin{gathered}
t^{\prime}{ }_{i}=-R_{i}{ }^{T} t_{i} \\
C_{i} R_{i}^{\prime} W=-C_{i} t_{i}^{\prime}
\end{gathered}
$$

Therefore, the next expression (6) is obtained from the data of two cameras.

$$
\begin{gathered}
B W=Y \\
B=\left(\begin{array}{l}
C_{1} R_{1}^{\prime} \\
C_{2} R_{2}^{\prime}
\end{array}\right) \\
Y=\left(\begin{array}{l}
-C_{1} t_{1}^{\prime} \\
-C_{2} t_{2}^{\prime}
\end{array}\right)
\end{gathered}
$$

$W$ is calculated with a pseudo-inverse matrix of $\mathrm{B}\left(B^{\#}\right)$.

$$
W=B^{\#} Y
$$

Calibrations were performed with a cube $\left(2 \mathrm{~cm}^{3}\right)$ made up of retroreflective markers, which were then used to calculate the matrix by each computer. In this study, the x-axis was classified as the direction from the "head to tail" of the pig, the y-axis was classified as the "left to right" side of the operating table, and the $\mathrm{z}$-axis was classified as the "upward" vertical angle from the pig (Figure 1).

\section{System Inspection}

This system was inspected before the animal experiments in three directions (x-axis, y-axis, and z-axis) using thrree stepping motors (Vexta; Suruga Seiki, Co, Shizuoka, Japan), which have an accuracy of $1 \mu \mathrm{m}$. A marker was continuously moved at a velocity of $1.0 \mathrm{~mm} / \mathrm{s}$ along each direction of axis, and motion tracking was done in each axis by this system $(n=5)$. The results of motion tracking are shown as Figure 3. Good results were obtained in each direction. When the computer processed the images at the maximum speed, average frame rate was $480 \pm 16$ fps $(\mathrm{n}=120)$. Tracking failure rate was $3 \%(n=100)$. The resulting accuracy of mean resolution was $70 \pm 6 \mu \mathrm{m}(\mathrm{n}=20)$. The tips of the endoscopes were set $10 \mathrm{~cm}$ from the markers for optimum resolution. All values such as velocity and acceleration were calculated on the computer processor simultaneously with the motion tracking.

\section{Data Acquisition}

The data of three regions of the LAD, the RCA, and the LCX artery were acquired for 10 seconds before and after stabilization by the Octopus tissue stabilizer (Medtronic, Inc, Minneapolis, Minn). Heart rates changed from 100 beats/min to 120 to 140 beats/min by atrial pacing. The apex-suction device (Starfish; Medtronic, Inc) was used to move the heart to access the target coronary artery on the lateral and inferior walls of the left ventricle. The Octopus tissue stabilizer was connected to the tail side of the retractor to stabilize the LAD and connected to the left side of the retractor to stabilize the RCA and LCX. Mechanical ventilation was stopped during data acquisition to avoid the influence of ventilation.

\section{Statistical Analysis}

Data are presented as mean \pm standard deviation.

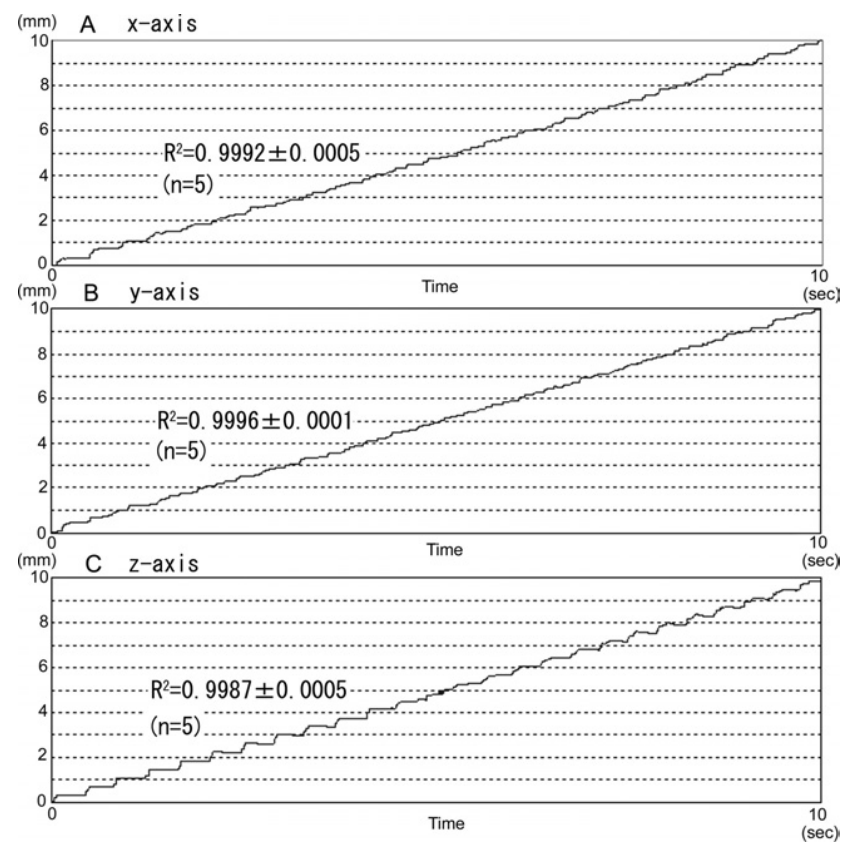

Figure 3. Inspection of the system in each axis using three stepping motors. Data are presented as mean \pm standard deviation.

Statistical analysis was performed for each parameter with the paired Student $t$ test. The following single-dimensional and 3-dimensional values were calculated. Each value was defined as follows:

(1) Move distance of 1 cardiac cycle ( $\mathrm{mm})$

$$
\begin{aligned}
& =\sum_{i=1}^{n} \operatorname{sqrt}\left[\{\mathrm{x}(\mathrm{i}+1)-\mathrm{x}(\mathrm{i})\}^{2}+\{\mathrm{y}(\mathrm{i}+1)-\mathrm{y}(\mathrm{i})\}^{2}\right. \\
& \left.+\{\mathrm{z}(\mathrm{i}+1)-\mathrm{z}(\mathrm{i})\}^{2}\right]
\end{aligned}
$$

$\mathrm{n}$ : frame rates/1 beat i: Variable $x(i), y(i), z(i)$ : coordinate position of marker at each axis

(2) Maximum velocity $(\mathrm{mm} / \mathrm{s})$

$$
\begin{aligned}
& =\operatorname{Max} \mid \operatorname{sqrt}\left[\{x(i+1)-x(i)\}^{2}+\{y(i+1)-y(i)\}^{2}\right. \\
& \left.+\{z(i+1)-z(i)\}^{2}\right] /\{\operatorname{time}(i+1)-\operatorname{time}(i)\} \mid
\end{aligned}
$$

(3) Average velocity $(\mathrm{mm} / \mathrm{s})$

$$
\begin{aligned}
& =\text { averagelsqrt }\left[\{\mathrm{x}(\mathrm{i}+1)-\mathrm{x}(\mathrm{i})\}^{2}+\{\mathrm{y}(\mathrm{i}+1)-\mathrm{y}(\mathrm{i})\}^{2}\right. \\
& +\{\mathrm{z}(\mathrm{i}+1)-\mathrm{z}(\mathrm{i})\}^{2} /\{\operatorname{time}(\mathrm{i}+1)-\operatorname{time}(\mathrm{i})\} \mid
\end{aligned}
$$

(4) Maximum acceleration $\left(\mathrm{m} / \mathrm{s}^{2}\right)$

$=\operatorname{Max}\{\{\operatorname{velocity}(i+1)-\operatorname{velocity}(i)\} /$

$\{$ time $(i+1)-$ time $(i)\}$ ।

(5) Maximum deceleration $\left(\mathrm{m} / \mathrm{s}^{2}\right)$

$=\operatorname{Min}\{\{\operatorname{velocity}(i+1)-\operatorname{velocity}(i)\} /$

$\{$ time $(i+1)-$ time $(i)\}$ |

(6) Maximum amplitude ( $\mathrm{mm})$

$=$ Max data - Min data of coordinate position of each axis at 1 beat 


\section{A Before Stabilization}
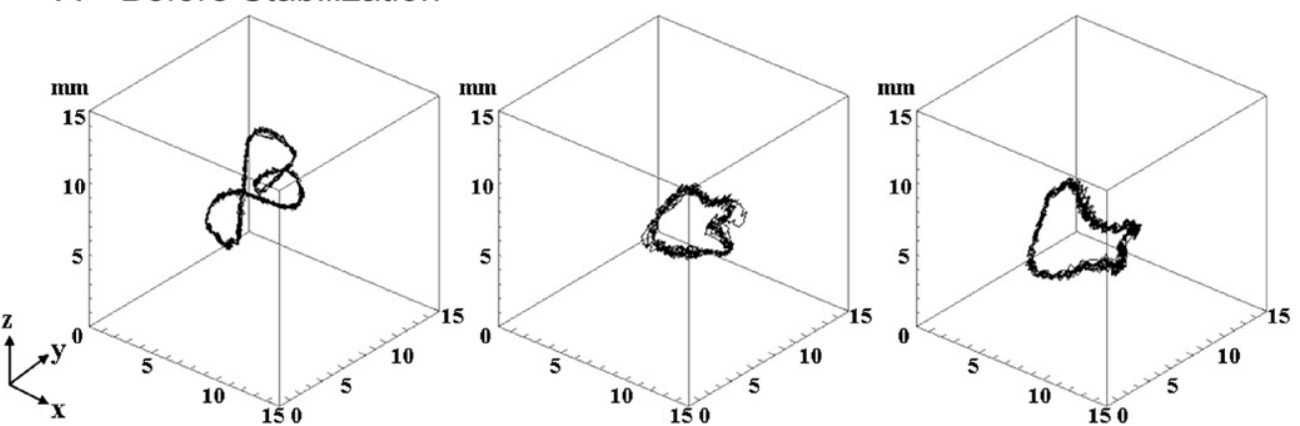

\section{B After Stabilization}

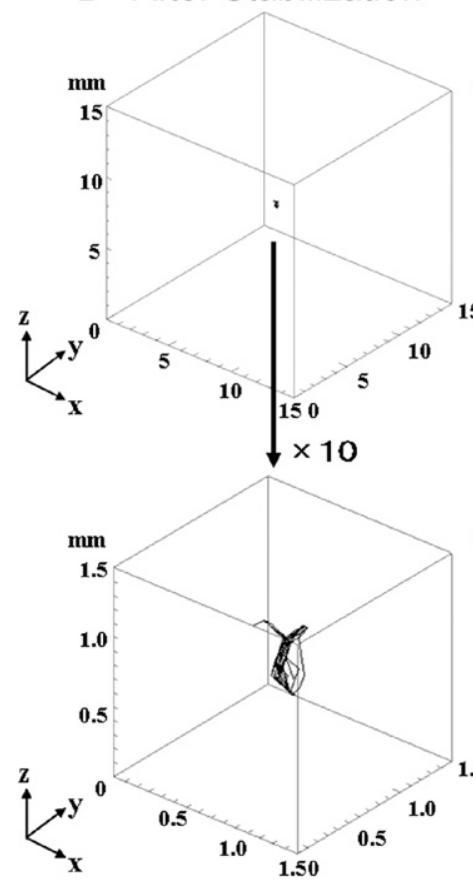

LAD
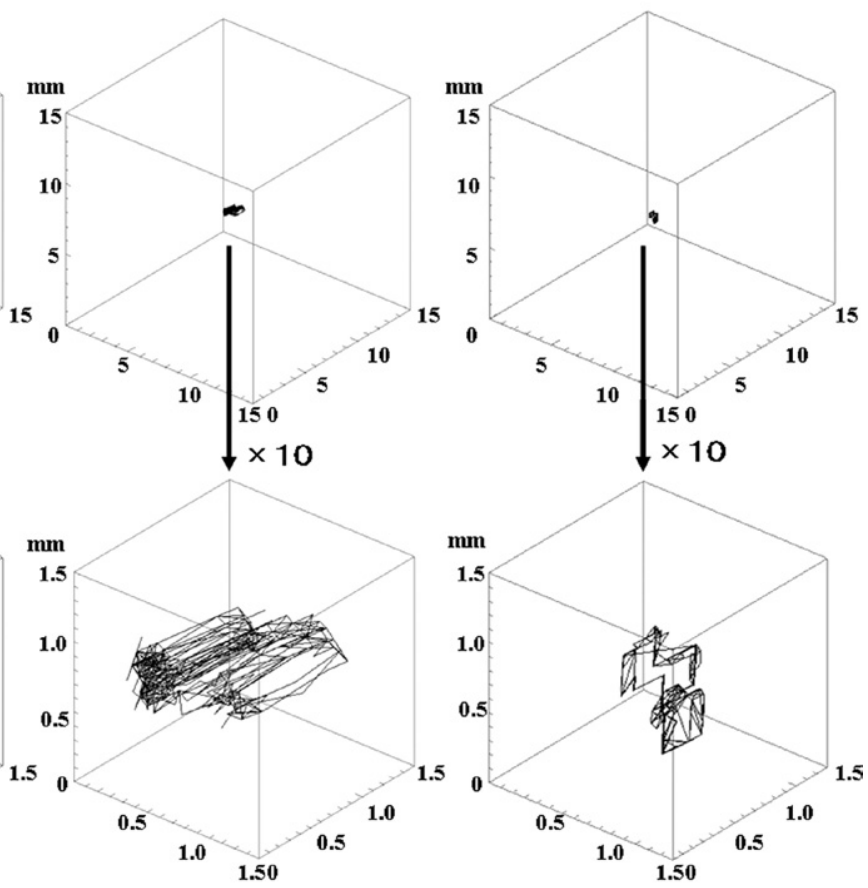

RCA

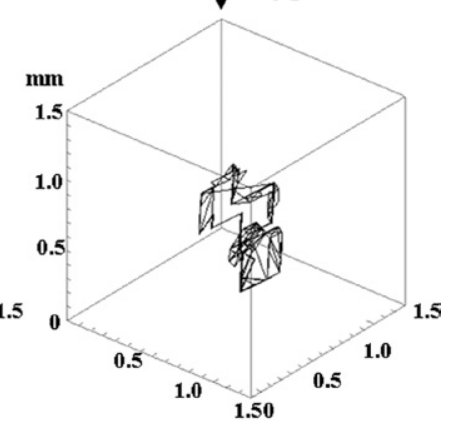

LCX

Figure 4. A representative 3-dimensional reconstruction of cardiac surface motion at left anterior descending artery (LAD), right coronary artery (RCA), and left circumflex artery (LCX) before stabilization ( $A$ ) and after stabilization (B).

Each value was calculated by each beat and averaged for 10 consecutive beats $(n=6)$.

\section{Results}

Virtual 3-dimensional images of a specific beating heart surface were successfully reconstructed by computer (Figure 4). The motion of each coronary artery is complicated, and differed with each pig. The movement along each axis was also analyzed in detail (Figure 5). Figure 5 shows that the movement of the coronary artery was influenced by mechanical ventilation (low-frequency motion pattern). In this study, because of analysis of the heart surface motion itself, all data were acquired without mechanical ventilation.
Percent rates of each value after stabilization compared with baseline are shown in Figure 6. Baseline is the value before stabilization. The distance moved in 1 cardiac cycle $(\mathrm{LAD} 15.9 \% \pm 6.7 \%, \mathrm{RCA} 34.5 \% \pm 19.2 \%, \mathrm{LCX} 16.6 \% \pm$ $6.2 \%$ ) and average velocity (LAD $15.8 \% \pm 6.4 \%$, RCA $34.3 \% \pm 18.1 \%$, LCX $17.2 \% \pm 5.8 \%$ ) were significantly reduced when compared with maximum velocity (LAD $62.5 \% \pm 23.6 \%, \operatorname{RCA} 76.4 \% \pm 15.3 \%, \operatorname{LCX} 68.5 \% \pm$ $25.0 \%$ ), maximum acceleration (LAD $65.3 \% \pm 22.0 \%$, RCA $75.2 \% \pm 14.9 \%, \operatorname{LCX} 69.9 \% \pm 28.4 \%)$, and maximum deceleration (LAD $64.1 \% \pm 21.7 \%$, RCA $75.2 \% \pm$ $16.0 \%$, LCX $63.3 \% \pm 21.8 \%)$ in the same group $(P<$ $.0001)$. Stabilization with the Octopus tissue stabilizer was 

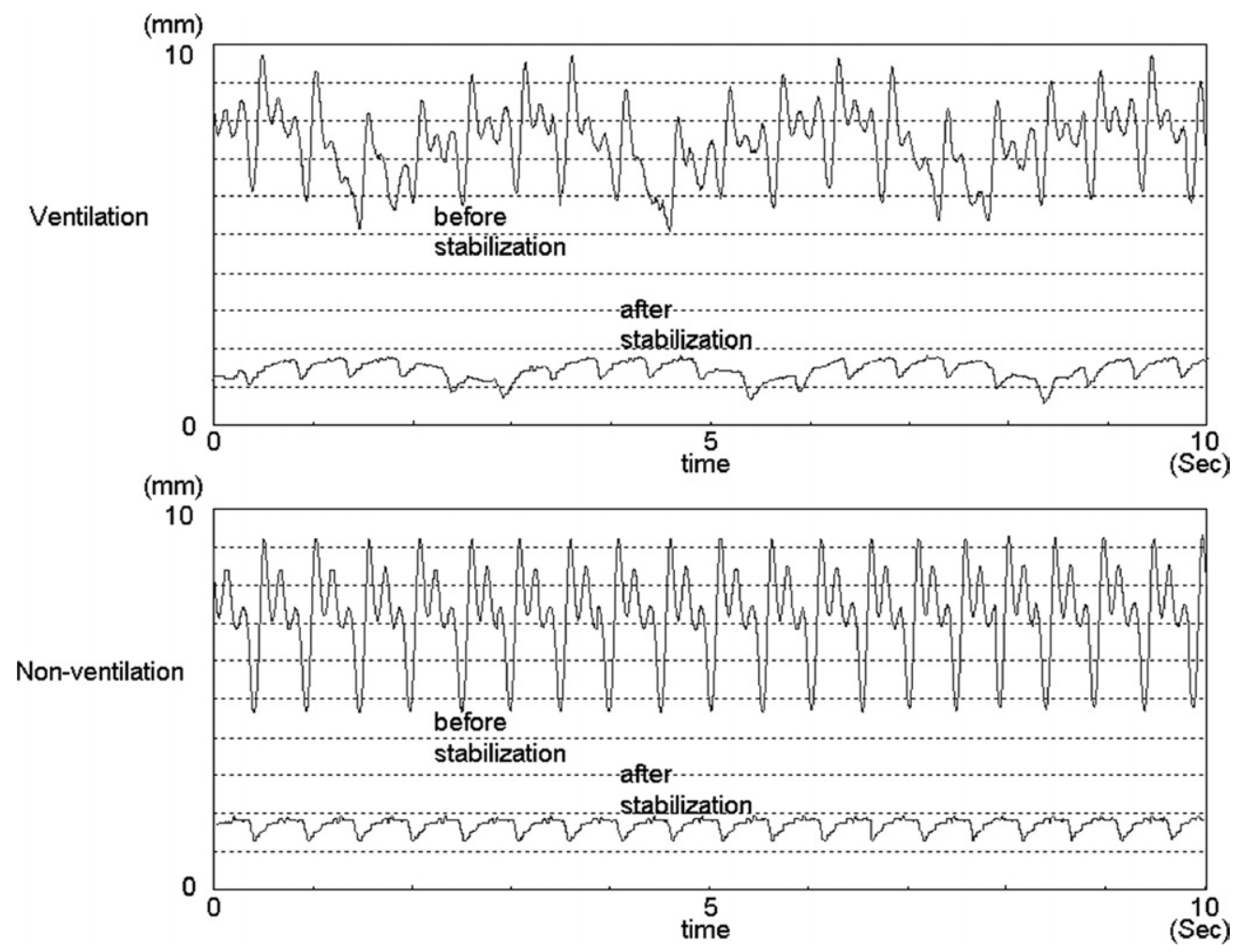

Figure 5. Plots of planar motion in $x$-axis at the LAD before and after stabilization. Upper panel is shown as under mechanical ventilation. Lower panel is shown as under non-mechanical ventilation.

more effective in the distance moved in 1 cardiac cycle and average velocity than maximum velocity, maximum acceleration, and maximum deceleration.

The breakdown of each axis is shown in Figure 7. Any value has shown a significant difference before and after stabilization $(P<.0001)$. In maximum amplitude, the remaining motion after stabilization was 0.4 to $1.01 \mathrm{~mm}$ at the LAD, 0.91 to $1.52 \mathrm{~mm}$ at the RCA, and 0.53 to $1.14 \mathrm{~mm}$ at the LCX. There was no significant difference in the ratio between each axis before or after stabilization. In maximum velocity, average velocity, and maximum acceleration, there were significant differences in the ratio between the $\mathrm{x}$-axis versus the $\mathrm{z}$-axis and between the $\mathrm{y}$-axis versus the $\mathrm{z}$-axis, especially at the RCA and LCX. Maximum velocity, average velocity, and maximum acceleration remained significantly higher in the z-axis (upward angle) at the RCA and LCX.

Concerning the heart rate and use of stabilizers (Figure 8), there was a tendency that the motion area of the heart would become smaller if the heart rates would increase. In our study, we tested at various heart rates and found that there were no significant differences at any coronary arteries. The noteworthy point is that the average velocity did not show a difference at different heart rates.

\section{Discussion}

A motionless surgical field is necessary for a precise coronary anastomosis. This field has been achieved with the use of cardiopulmonary bypass and cardiac arrest. OPCAB has an advantage of avoiding the adverse effects of cardiopulmonary bypass such as the inflammation throughout the body, hematologic problems, and neurocognitive changes. In OPCAB, there was a technical difficulty in the anastomosis of the coronary arteries of 1.5 to $2.0 \mathrm{~mm}$ in diameter with the beating heart. Various methods of mechanical stabilization and/or pharmacologic stabilization of the beating heart have been devised and examined. ${ }^{10,11,18-20}$ After a motionless field has been achieved by mechanical stabilization, similar to cardiac arrest with cardiopulmonary bypass, OPCAB has become more frequent in surgical procedures. However, stabilization has been left to a subjective evaluation by surgeons. Therefore, various methods of stabilization could not be evaluated comparably and scientific objective evaluation was impossible.

When we try to analyze the difficulty of anastomosis, there are two factors to consider: the analysis of the movement around the target point and the surgical factors involved. ${ }^{21-26}$ 
Rate (\%) of after stabilization compared with baseline
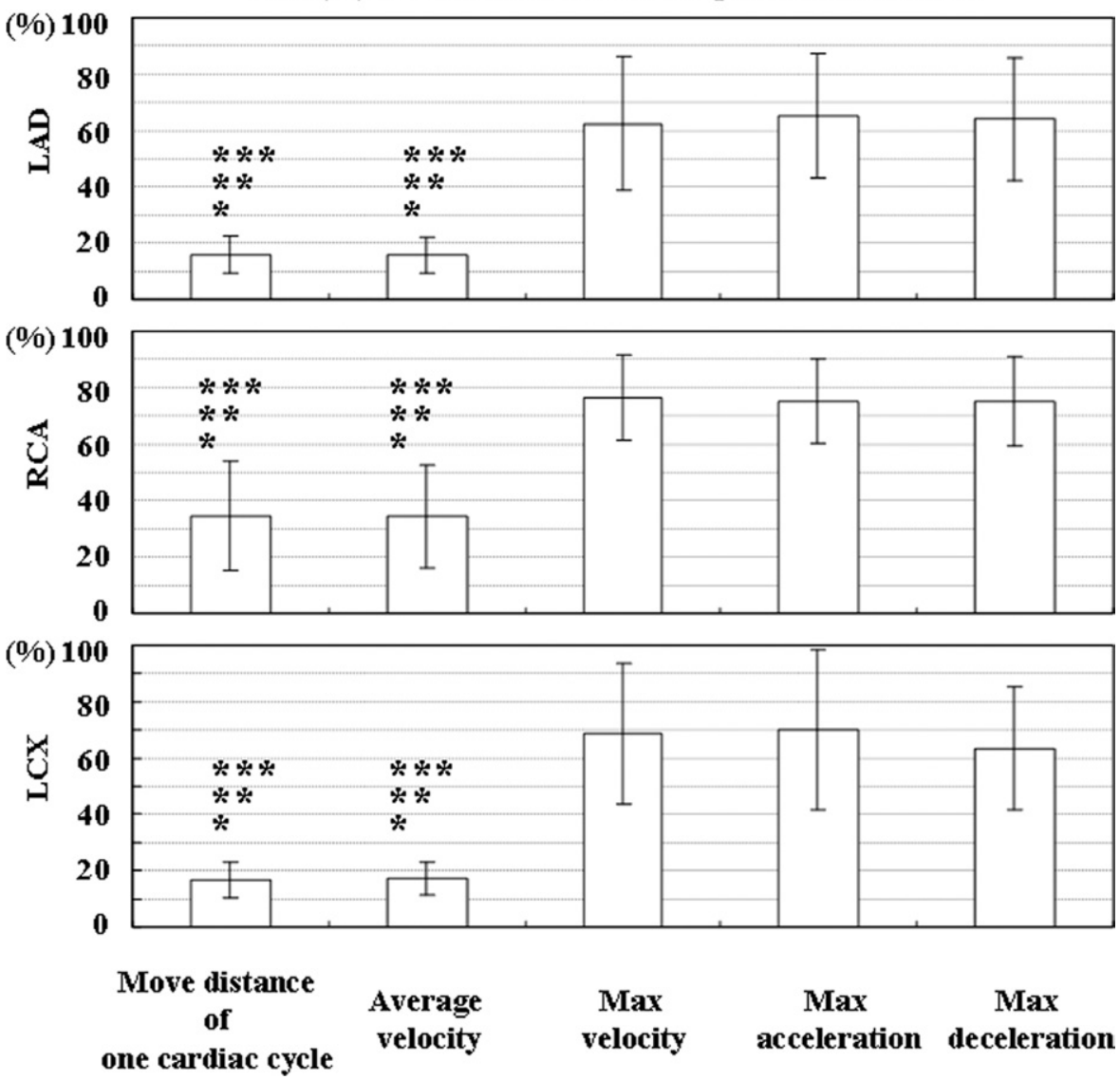

Figure 6. Graphs of rate (\%) after stabilization compared with baseline. Baseline is value before stabilization. Vertical bars are standard deviation. ${ }^{*} \boldsymbol{P}<.0001$ compared with maximum velocity. ${ }^{* *} P<.0001$ compared with maximum acceleration. ${ }^{* * *} P<.0001$ compared with maximum deceleration. $L A D$, Left anterior descending coronary artery; $R C A$, right coronary artery; $L C X$, left circumflex coronary artery.
In 1964, Fitts and Peterson ${ }^{21}$ described the difficulty of touching a target, which is known as Fitt's law. In this law, the difficulty in touching a target is decreased by decreasing the distance between the target and the operator. The difficulty is also decreased by increasing the target width. Because this law was made with a nonmoving target, Jagacinski and his colleagues ${ }^{22}$ modified this law, by describing that the degree of difficulty is increased by increasing the target velocity. The geometric accuracy of surgeons is limited to the range between 100 and $200 \mu \mathrm{m} .^{23}$ Even for a surgeon under ideal conditions (with the elbows at rest and a microscopic view), the geometric accuracy may not exceed $50 \mu \mathrm{m} .{ }^{23}$ In other words, the geometric accuracy to aim a needle at the desired target (arterial wall) under ideal conditions (nonmoving target) will be in the range of 0.1 to $0.2 \mathrm{~mm} .{ }^{26}$ Previous studies have shown that the motion of the fingers and hand are typically performed at low frequencies of 4 to $7 \mathrm{~Hz}$ and the limit of tracking performance for a human is about $1 \mathrm{~Hz}^{24,25}$ Because $1 \mathrm{~Hz}$ equals 60 beats/ $\mathrm{min}$, under 60 beats/min is considered to be the ideal rate for the surgeon to have the most control and ability to track a target point. ${ }^{1,26}$ The heart surgeon can also gain more control over these difficulties with the aid of magnifying glasses and/or arresting the heart. In beating heart surgery, a stabilizing devise has been developed to keep the motion of the target area within limits. Mechanical stabilization with a stabilizer has widely increased in recent years.

Despite the natural motion of target areas during surgical procedures, which is an important issue for cardiac surgeons to consider, there have been only a few reports that analyze cardiac surface motion. Several attempts to evaluate the cardiac surface motion quantitatively have recently been reported.

In 1996, Borst and associates ${ }^{5}$ reported that a mechanical stabilizer (Octopus; Medtronic, Inc) significantly reduced the area circumscribed by the 2-dimensional reference points on the RCA and obtuse marginal branch in pigs by using an analog video camera. In 2002, Detter and associates ${ }^{6}$ measured the deviation of small vessels in the anterior wall before and after stabilization by using an orthogonal polarizations spectral imaging device, reporting that the deviation was decreased significantly with the aid of an Octopus stabilizer. In 2003, Koransky and associates ${ }^{7}$ 3-dimensionally reconstructed the motion of the LAD for the first time with digital sonomicrometry. They reported that stabilization significantly reduced the 3-dimensional 

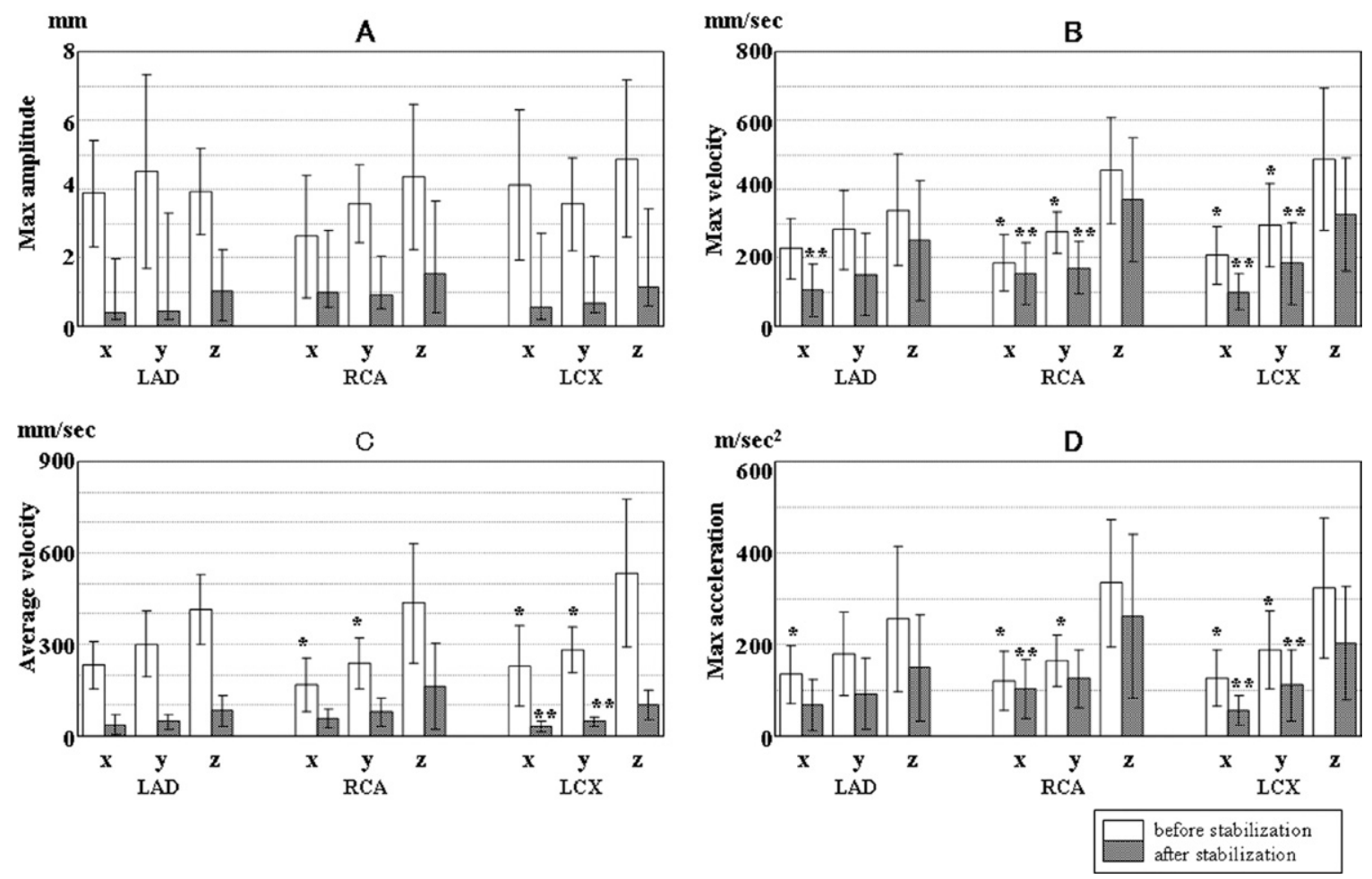

Figure 7. Comparison of single-axis Cartesian maximum amplitude (A), maximum velocity (B), average velocity (C), and maximum acceleration (D) before and after stabilization at each axis. Vertical bars are standard deviation. ${ }^{*} \boldsymbol{P}<.0001$ compared same group with $\mathrm{z}$-axis before stabilization. ${ }^{*} \boldsymbol{P}<.0001$ compared same group with $\mathrm{z}$-axis after stabilization. $L A D$, Left anterior descending coronary artery; $R C A$, right coronary artery; $L C X$, left circumflex coronary artery.

excursion, maximum velocity, and average velocity. In 2004, Cattin and associates ${ }^{8}$ captured the wall movements of the heart by using a high-speed camera coupled with a laser sensor. The 2-dimensional lateral motion was captured with the high-speed camera and the out-of-plane motion was acquired with the laser sensor. Most recently, in 2005, Lemma and associates ${ }^{9}$ captured the coronary artery simultaneously with two digital cameras, reconstructing the wall movements of the heart in 3-dimensional fashion. This was the first quantitative analysis of the three regions of LAD, RCA, and LCX.

Our newly developed system has several advantages over previous studies. First, our system is able to reconstruct the 3-dimensional motion of any coronary arteries in real time. Since the endoscopic camera can move freely and observe in detail, any area of cardiac motion can be focused on and captured. Second, the acquired 3-dimensional data can compare every region and every axis. Because the axis can be freely set up during calibration, it is possible to change any axis before and after data acquisition. With the data received, there will be a complete record of all of the movements in an entire operation. Third, the use of an endoscope can greatly decrease the distance to the target point. The zoom, focus, and resolution can also be adjusted with the high-speed camera and/or the endoscope. Fourth, markers were devised to help control the accuracy of the system. These markers are small and lightweight. They can be placed on any surgical surface and will help lock in on any target point when used with the endoscope. Finally, both the endoscope and the markers can be sterilized and used in any medical procedure or operation in their sterilized state.

In this experiment, every value showed that the motion of the coronary artery was reduced significantly after stabilization at three regions. ${ }^{5-9}$ We reached several new conclusions. First, the maximum acceleration and the maximum velocity were not reduced significantly compared with maximum amplitude and the motion distance of 1 cardiac cycle. The rapid and sudden motion did remain during stabilization. This phenomenon was apparent especially in the direction of the z-axis of the RCA and LCX. The stabilizer needs to be improved to reduce rapid and sudden motion, especially in the z-axis (upward angle). Second, as the heart rates increase, the motion distance of 1 cardiac cycle, max- 

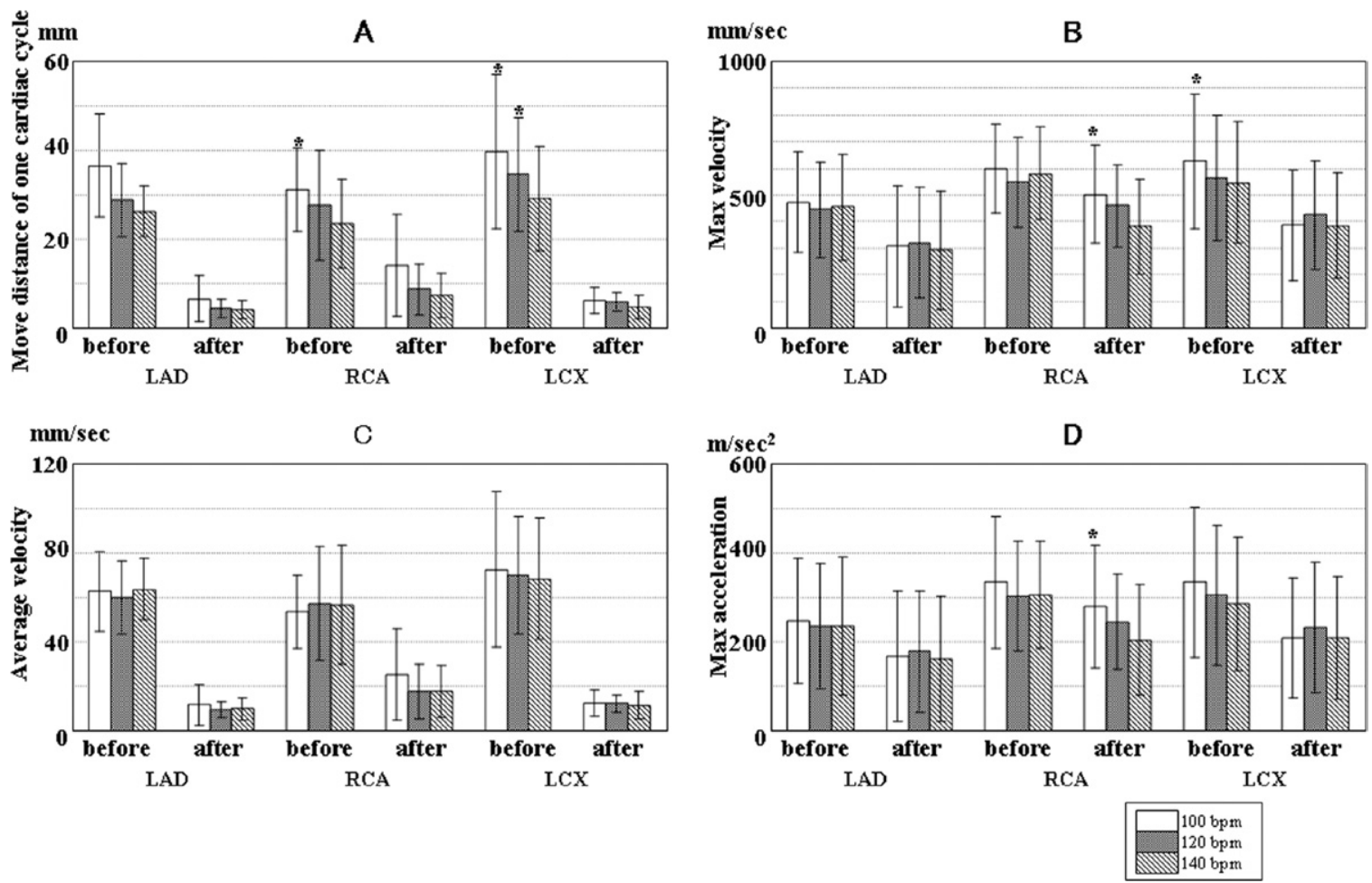

Figure 8. Comparison of 3-dimensional Cartesian move distance of 1 cardiac cycle (A), maximum velocity (B), average velocity (C), and maximum acceleration (D) before and after stabilization at heart rates of 100, 120, and 140 beats/min. Vertical bars are standard deviation. ${ }^{*} P<.01$ compared same group with 140-beats/min heart rates. $L A D$, Left anterior descending coronary artery; $R C A$, right coronary artery; $L C X$, left circumflex coronary artery.

imum velocity, and maximum acceleration decreased, while average velocity did not change significantly. Falk ${ }^{26}$ reported that the difficulty of motion tracking would increase when the heart rates increases. In our study, the motion distance of 1 cardiac cycle decreased and average velocity did not change. In beating heart surgery, the difficulty is most influenced by the heart rate and the rapid and sudden motion, the maximum velocity, and the maximum acceleration.

\section{Clinical Implications}

Our system can improve a mechanical stabilizer by using the values obtained in this study. Our system can also improve the needed skill pertaining to heart surgery. Although some different thoughts and ideas have been developed, none has been able to reproduce cardiac surface motion. ${ }^{1,26,27-30}$ Unfortunately, they are inadequate and not practical. More systems need to be built that are able to reproduce the cardiac surface motion. The digital coordinate data that can be produced and obtained from our system are indispensable to future systems.

Finally, our system can also be used in robotic surgery. Robotic surgery on the beating heart using motion- canceling algorithms has been developed. ${ }^{2,3}$ The data that our system can provide can be an indispensable addition to the future use and development of a motion-canceling system and robotic surgery.

\section{Limitations}

There are some limitations to this technique. Since the cube is used for calibration, if two cameras are near, the cube is not recognized at different angles. Therefore, it is necessary to maintain an angle from $45^{\circ}$ to $135^{\circ}$ between the two cameras. After calibration, the two cameras cannot be moved. About $10-\mathrm{cm}$ distance or more is required between the target point and the tip of an endoscope because a calibration cannot be carried out if a cube is out of the screen. When a marker is hidden by something, such as the chest wall or a retractor, two cameras must be moved to the position where a marker is seen. Two cameras can be moved freely in all directions. However, when a marker is obscured, it is impossible to acquire data.

\section{Conclusions}

This innovative system plausibly can obtain 3-dimentional position data of any part of the beating heart surface. Our 
system is useful for an accurate quantification of the heart surface motion. Our system can help us all better understand the complexity of the beating heart and can help to develop a better stabilizer and ideas for beating heart surgery. ${ }^{4,12-16}$

\section{References}

1. Jacobs S, Holzhey D, Kiaii BB, Onnasch JF, Walther T, Falk V, et al. Limitation for manual and telemanipulator-assisted motion trackingimplications for endoscopic beating-heart surgery. Ann Thorac Surg. 2003;76:2029-36.

2. Nakamura Y, Kishi K. Robotic stabilization that assists cardiac surgery on beating hearts. Stud Health Technol Inform. 2001;81:355-61.

3. Ortmaier T, Groger M, Dieter HB, Falk V, Hirzinger G. Motion estimation in beating heart surgery. IEEE Trans Biomed Eng. 2005; 52:1729-40.

4. Ingels NB Jr, Daughters GT, Davies SR, MacDonald IB. Stereo photogrammetric studies on the dynamic geometry of the canine left ventricular epicardium. J Biomach. 1971;4:541-50.

5. Borst C, Jansen EW, Tulleken CA, Grundeman PF, Mansvelt Beck HJ, van Dongen JW, et al. Coronary artery bypass grafting without interruption of native coronary flow using a novel anastomosis site restraining device ("Octopus"). J Am Coll Cardiol. 1996;27:1356-64.

6. Detter C, Deuse T, Christ F, Boehm DH, Reichenspurner H, Reichart B. Comparison of two stabilizer concepts for off-pump coronary artery bypass grafting. Ann Thorac Surg. 2002;74:497-501.

7. Koransky ML, Tavana ML, Yamaguchi A, Kown MH, Miniati DN, Robbins RC, et al. Quantification of mechanical stabilization for the performance of off-pump coronary artery surgery. Heart Surg Forum. 2003;6:224-31.

8. Cattin P, Dave H, Grunenfelder J, Szekely G, Turina M, Zund G. Trajectory of coronary motion and its significance in robotic motion cancellation. Eur J Cardiothorac Surg. 2004;25:786-90.

9. Lemma M, Mangini A, Redaelli A, Acocella F. Do cardiac stabilizers really stabilize? Experimental quantitative analysis of mechanical stabilization. Interactive Cardiovasc Thorac Surg. 2005;4:222-6.

10. Bel A, Perrault LP, Faris B, Mouas C, Vilaine JP, Menasché P. Inhibition of the pacemaker current: a bradycardic therapy for offpump coronary operations. Ann Thorac Surg. 1998;66:148-52.

11. Gulielmos V, Kappert U, Eller M, Sahre H, Alexiou K, Georgi C, et al. Improving hemodynamics by atrial pacing during off-pump bypass surgery. Heart Surg Forum. 2003;6:179-82.

12. Olson CF. Maximum-likelihood template matching. In: Proceedings of the IEEE Conference on Computer Vision and Pattern Recognition. Washington, DC: IEEE Computer Society. 2000;2:52-5.

13. Ben-Arie J, Wang Z. Estimation of 3D motion using eigen-normalization and expansion matching. IEEE Trans Image Processing. 2000;9:1636-40.
14. Gharavi-Alkhansari M. A fast globally optimal algorithm for template matching using low-resolution pruning. IEEE Trans Image Processing. 2001;10:526-33.

15. Jurie F, Dhome M. Hyperplane approximation for template matching. IEEE Trans Pattern Analysis and Machine Intelligence. 2002;24:9961000.

16. Dufour RM, Miller EL, Galatsanos NP. Template matching based object recognition with unknown geometric parameters. IEEE Trans Image Processing. 2002;11:1385-96.

17. Olivier F. Stereo vision. In: Three dimensional computer vision. London: MIT Press; 1993. p. 165-244.

18. Yukio K, Kageharu K, Kazufumi M, Shimoji M, Tooru U, Katuya A, et al. Management of the heart rate during coronary artery bypass grafting on the beating heart: newly devised methods of decreasing heart rate-a preliminary report. Ann Thorac Cardiovasc Surg. 2001; 7:358-67.

19. Robinson MC, Thielmeier KA, Hill BB. Transient ventricular asystole using adenosine during minimally invasive and open sternotomy coronary artery bypass grafting. Ann Thorac Surg. 1997;63:S30-4.

20. Jansen E, Grundeman P, Borst C, Eefting F, Diepuis J, Nierich A, et al. Less invasive off-pump CABG using a suction device for immobilization: the 'octopus' method. Eur J Cardiothorac Surg. 1997; 12:406-12.

21. Fitts PM, Peterson JR. Information capacity of discrete motor responses. J Exp Psychol. 1964;67:103-12.

22. Jagacinski RJ, Repperger DW, Moran MS, Ward SL, Glass B. Fitts' law and the microstructure of rapid discrete movements. J Exp Psychol. 1980;63:309-20.

23. Taylor RH, Jensen P, Whitcomb LL, Barnes A, Kumar R, Stoianovici $\mathrm{D}$, et al. A steady-hand robotic system for microsurgical augmentation. Rob Res. 1999;12:1201-10.

24. Kunesch E, Binkofski F, Freund HJ. Invariant temporal characteristics of manipulative hand movements. Exp Brain Res. 1989;78:539-46.

25. Robert W. Selection and control of action: In: Salvendy G, editor. Handbook of human factors and ergonomics. 3rd ed. Hoboken: John Wiley and Sons; 2006. p. 89-110.

26. Falk V. Manual control and tracking-a human factor analysis relevant for beating heart surgery. Ann Thorac Surg. 2002;74:624-8.

27. Izzat MB, El-Zufari MH, Yim APC. Training model for "beatingheart" coronary artery anastomosis. Ann Thorac Surg. 1998;66:580-1.

28. Stanbridge RL, O'Regan D, Cherian A, Ramanan R. Use of a pulsatile beating heart model for training surgeons in beating surgery. Heart Surg Forum. 1999;2:300-4.

29. Reuthebuch O, Lang A, Groscurth P, Lachat M, Turina M, Zund G. Advanced training model for beating heart coronary artery surgery: the Zurich heart-trainer. Eur J Cardiothorac Surg. 2002;22:244-8.

30. Ramphal PS, Coore DN, Craven MP, Forbes NF, Newman SM, Coye AA, et al. A high fidelity tissue-based cardiac surgical simulator. Eur J Cardiothorac Surg. 2005;27:910-6. 